\title{
DYNAMIC OF UPPER LIMB SENSORIMOTOR RECOVERY ASSESSED ON THE FUGL-MEYER SCALE IN POST-STROKE PATIENTS WITH NEGLECT SYNDROME RECEIVING COMBINED PHYSICAL THERAPY AND ERGOTHERAPY
}

D0I: $10.36740 /$ WLek202104107

\author{
Yurii M. Dido, Olena A. Dulo \\ UZHHOROD NATIONAL UNIVERSITY, UZHHOROD, UKRAINE
}

\begin{abstract}
The aim: To assess the effect of the modified combined program of physical therapy and ergotherapy on the indicators of upper limb recovery in the patients with the left unilateral neglect.

Materials and methods: The study involved 58 patients diagnosed with the right hemisphere stroke followed by neglect syndrome. Patients were randomly divided into main group (MG) and control group (CG) according to the ratio of 1:1. Physical therapy of (G patients included proprioceptive neuromuscular facilitation (PNF), balance training, ergotherapeutic intervention, and exercises improving fine motor skills. Specially developed intervention program of MG patients took into account patient's individual capabilities and needs. It included PNF, balance training and upright posture correction, constraint-induced movement therapy, dual task activities, stimulation of the affected side in daily activities, targeted therapy. The length of intervention comprised 3 months in both groups.

Results: According to the results of the primary examination, the groups had no differences in demographic variables, clinical history (NIHSS scale, the Glasgow Coma Scale and Albert's Test) and Fugl-Meyer assessment of upper limb sensorimotor recovery. Statistical analysis of the final scores of the Fugl-Meyer scale confirmed that MG had statistical advantages in all measured items of the motor function domain, as well as in a number of proprioceptive sensitivity indicators.

Conclusions: The obtained results confirm better efficacy of the modified program of physical therapy and ergotherapy, received by MG patients.
\end{abstract}

KEY WORDS: left unilateral neglect, balance training, constraint-induced movement therapy, dual task activities

Wiad Lek. 2021;74(4):849-855

\section{INTRODUCTION}

The consequences of past cerebral circulatory disorders lead to a serious decrease of patients' life quality. Being the main reason for progressive and long-term disability of the population, stroke remains one of the most important challenges of modern society $[1,2]$.

Depending on the location and extent of brain morphological changes following the stroke, the clinical picture and movement disorders can vary significantly $[3,4]$.

A few days after onset, when cerebral disorders are smoothed, priority is taken by movement disorders, which depend on the location of the pathological process. Movement disorders in the acute period develop in $75 \%$ of patients, and six months later movement defects persist in $53 \%$ of patients [3].

Neglect syndrome is observed in case of large damages of back (parietal or parieto-occipital) lobes mainly of the right hemisphere. There are opinions that the development of this syndrome involves thalamus, basal ganglia, corpus callosum, frontal, parietal and temporal lobes, reticular formation, other non-specific parts of the brain affected by stroke [5-7].

According to various authors, this syndrome is observed in $33-85 \%$ of patients with right hemispheric stroke and $24 \%$ of patients with left hemispheric stroke [8].
Such patients do not tell about their complaints in the conversation, considering themselves "completely healthy" and claiming that their left limbs function just as well as the right limbs. Patients are passive about the existence of the disorder, rehabilitation process and obtained positive results, and usually cannot sufficiently implement their movement functions $[9,10]$.

Spatial (visual) neglect can be diagnosed with the help of Albert's test, which enables to detect and quantify it. The percentage of missed segments correlates with the degree of cognitive function restoration six months after the test [1].

On the other hand, one of the most important causes of disability after stroke is arm impairment, which occurs in $70 \%$ of the patients with past acute cerebral circulatory disorders [11]. In this case upper limb function recovery usually [12] occurs at a later date, often remaining the only reason for patient's disability. Upper limb function is completely restored only in $20 \%$ of patients $[11,13,14]$.

The main approach, continually applied in the treatment and rehabilitation of neglect, directly addresses the problem of the main deficit of neglect and attempts to refocus attention on the neglected side. Visual scanning therapy is widely used in neglect rehabilitation, basically encouraging 
the patients to study, for example, the left side of space, often with the help of visual signals $[15,16]$.

Neglect following acute cerebral circulatory disorder was proved to affect the quality of rehabilitation [15], namely to prolong the length of hospital stay, increase the risk of falling, reduce the chances of returning home after intensive inpatient rehabilitation, i.e. the patient with neglect cannot be completely self-supporting [17].

Taking into account the available data, improving the results of physical therapy and ergotherapy in stroke patients with neglect syndrome is an important task.

\section{THE AIM}

The aim was to assess the effect of the modified combined program of physical therapy and ergotherapy on the indicators of upper limb sensorimotor recovery in the patients with the right hemisphere ischemic acute cerebral circulatory disorders followed by neglect syndrome.

\section{MATERIALS AND METHODS}

Participants: The study involved 58 patients $(29$ females and 29 males) diagnosed with the right hemisphere ischemic acute cerebral circulatory disorder followed by neglect syndrome. All persons were informed about the content of the tests, measurement procedures and signed an informed consent form. The research was approved by the Institutional Ethics Committee (number 1/2017) and was carried out in compliance with the international principles of the Helsinki Declaration of the World Medical Association [18], and in accordance with the Law of Ukraine "Fundamentals of Ukrainian Legislation on Healthcare" [19] on ethical norms and rules for conducting medical research involving human.

The patients were randomly divided into main group (MG) and control group (CG) according to the ratio of 1:1. The exclusion criteria were hemianopsia, scores above 3 on the Scale of Contraversive pushing, scores above 14 on the NIHSS scale.

Setting: hospitalized care and home-based rehabilitation program.

Interventions: Physical therapy of CG patients included proprioceptive neuromuscular facilitation (PNF), balance training, ergotherapeutic intervention, and exercises impoving fine motor skills. Specially developed intervention program of MG patients took into account patient's individual capabilities and needs, after analyzing the obtained results. The Predict Recovery Potential (PREP2) algorithm was used to predict upper limb recovery interventions. Goal setting employed SMART goals framework. The SOAP format was used for therapy planning.

PNF (scapular and upper limb patterns), constraint-induced motor therapy (SIMT) and dual task activities were used. The intervention included balance exercises while sitting and standing, as well as neglect correcting exercises, namely: - stimulation of the affected side (tactile, visual, motor);

- constant drawing attention to the affected side of the space (wearing bright bracelets on the left hand, placing photos of significant people and bright objects on the left side); - involvement of the affected side in daily activities (placing food (not hot) on the affected side, approaching the patient by specialists and relatives from the neglected side, placing board games, means of communication on the neglected side);

- patients were also asked to place clock hands according to the given time; complete missing parts of the objects, letters and numbers in the pictures; replicate specific patterns in the Kohs Block test, create patterns using tactile (tactile-colored) dominoes; find the middle of the length; cross out the numbers in the right and left halves of the sheet; work on sheets divided in half; draw symmetrical pictures; move hands alternately and simultaneously, etc. The therapy was performed 5 days a week for $14 \pm 4.2$ days, and then 3 times a week for up to three months in both groups.

Three months later, the patients had a repeated, final examination.

Outcome Measures: Demographic variables, clinical history (NIHSS scale, the Glasgow Coma Scale and Albert's Test scores). Comparing the efficacy of the combined program of physical therapy and ergotherapy in CG and MG was carried out using indicators of upper limb sensorimotor recovery according to Fugl-Meyer scale.

Statistical analysis: The materials of the research were processed in IBM SPSS 21.0 program (Chicago, IL, USA) of statistical analysis. The analysis of quantitative indicators distribution's correspondence to the law of normal distribution was checked by Shapiro-Wilk test (W). Mean value \pm standard deviation $( \pm S D)$ were calculated for the results of indicators that corresponded to the law of normal distribution. Median value (Me) and upper and lower quartiles (25\%; 75\%) were calculated for the indicators with a non-normal distribution. Student's t-test (for independent groups) was used to measure the significance of the difference, provided there was a normal distribution of study results; Mann-Whitney $U$ test (for independent groups) and $\chi^{2}$ criterion were used provided the indicators had a distribution other than normal.

\section{RESULTS}

CG included 13 males and 16 females, whereas MG included 16 males and 13 females ( $p>0.05)$. The mean age of CG patients was $69.3 \pm 9.77$ years, and the mean age of MG patients was $67.9 \pm 10.46$ years $(\mathrm{p}>0.05)$. During first examination of CG, 5 patients had satisfactory health condition, 12 patients had health condition close to satisfactory, 6 patients had moderately severe condition, and 6 patients had severe health condition. Among MG patients, 6 patients had satisfactory health condition, 15 patients had health condition close to satisfactory, 5 patients had moderately severe condition, and 3 patients had severe health condition. Statistical analysis did not reveal any significant difference in this distribution of patients $(\mathrm{p}>0.05)$.

According to the NIHSS Scale, the average value in CG was $8.41 \pm 2.31$ with $\mathrm{Me}(25 \%$; $75 \%)$ indicator being 9 (7; 
Table I. Initial Fugl-Meyer scores of sensorimotor recovery in groups of patients

\begin{tabular}{|c|c|c|c|c|c|}
\hline & \multirow{2}{*}{ Items } & \multicolumn{2}{|c|}{$\begin{array}{c}\text { CG } \\
(n=29)\end{array}$} & \multicolumn{2}{|c|}{$\begin{array}{c}\text { MG } \\
(n=29)\end{array}$} \\
\hline & & $\overline{\mathbf{x}} \pm \mathbf{S D}$ & $\begin{array}{c}\text { Me } \\
(25 \% ; 75 \%)\end{array}$ & $\overline{\mathbf{x}} \pm \mathbf{S D}$ & $\begin{array}{c}\text { Me } \\
(25 \% ; 75 \%)\end{array}$ \\
\hline \multirow{4}{*}{ 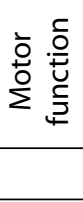 } & Proximal part of the arm & $11.10 \pm 1.82$ & $11(9.5 ; 12.5)$ & $11.31 \pm 1.79$ & $12(10 ; 12.5)$ \\
\hline & Hand and radiocarpal joint & $5.07 \pm 1.10$ & $5(4 ; 6)$ & $5.07 \pm 1.22$ & $5(4 ; 6)$ \\
\hline & Total score of the upper limb & $16.17 \pm 2.87$ & $16(13.5 ; 18.5)$ & $16.38 \pm 2.93$ & $17(14 ; 18)$ \\
\hline & Balance & $6.03 \pm 0.91$ & $6(5 ; 7)$ & $6.24 \pm 0.91$ & $6(6 ; 7)$ \\
\hline \multirow{6}{*}{ 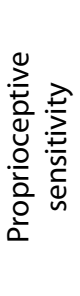 } & Shoulder joint & $0.86 \pm 0.58$ & $1(0,5 ; 1)$ & $0.93 \pm 0.37$ & $1(1 ; 1)$ \\
\hline & Elbow joint & $0.79 \pm 0.49$ & $1(0,5 ; 1)$ & $0.83 \pm 0.53$ & $1(0.5 ; 1)$ \\
\hline & Radiocarpal joint & $0.72 \pm 0.53$ & $1(0 ; 1)$ & $0.76 \pm 0.56$ & $1(0 ; 1)$ \\
\hline & Fingers & $0.76 \pm 0.58$ & $1(0 ; 1)$ & $0.83 \pm 0.60$ & $1(0 ; 1)$ \\
\hline & Thumb & $0.86 \pm 0.64$ & $1(0 ; 1)$ & $0.90 \pm 0.49$ & $1(1 ; 1)$ \\
\hline & Total sensitivity of the upper limb & $10.03 \pm 1.97$ & $10(8.5 ; 12)$ & $10.48 \pm 1.86$ & $11(9 ; 12)$ \\
\hline
\end{tabular}

CG - control group; $M G$ - main group.

Table II. Final Fugl-Meyer scores of sensorimotor recovery in groups of patients

\begin{tabular}{|c|c|c|c|c|c|}
\hline & \multirow{2}{*}{ Items } & \multicolumn{2}{|c|}{$\begin{array}{c}\text { CG } \\
(n=29)\end{array}$} & \multicolumn{2}{|c|}{$\begin{array}{c}\text { MG } \\
(n=29)\end{array}$} \\
\hline & & $\overline{\mathbf{x}} \pm \mathbf{S D}$ & $\begin{array}{c}\text { Me } \\
\text { (25\%; 75\%) }\end{array}$ & $\overline{\mathbf{x}} \pm \mathbf{S D}$ & $\begin{array}{c}\text { Me } \\
(25 \% ; 75 \%)\end{array}$ \\
\hline \multirow{4}{*}{ 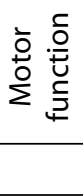 } & Proximal part of the arm & $22.81 \pm 5.42$ & $24(18 ; 27)$ & $27.72 \pm 5.00$ & $30(25 ; 31.5)^{* *}$ \\
\hline & Hand and radiocarpal joint & $16.53 \pm 4.20$ & $17(12 ; 21)$ & $20.00 \pm 4.69$ & $21(15 ; 24.5)^{* *}$ \\
\hline & Total score of the upper limb & $39.34 \pm 8.36$ & $41(33.5 ; 47)$ & $47.72 \pm 8.81^{* *}$ & $49(45 ; 54.5)$ \\
\hline & Balance & $9.78 \pm 1.72$ & $11(8 ; 11)$ & $10.79 \pm 2.30$ & $12(9.5 ; 12.0)^{* *}$ \\
\hline \multirow{6}{*}{ 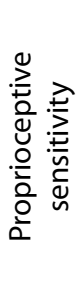 } & Shoulder joint & $1.52 \pm 0.51$ & $2(1 ; 2)$ & $1.83 \pm 0.38$ & $2(2 ; 2)^{*}$ \\
\hline & Elbow joint & $1.66 \pm 0.48$ & $2(1 ; 2)$ & $1.72 \pm 0.45$ & $2(1 ; 2)$ \\
\hline & Radiocarpal joint & $1.55 \pm 0.51$ & $2(1 ; 2)$ & $1.59 \pm 0.50$ & $2(1 ; 2)$ \\
\hline & Fingers & $1.31 \pm 0.47$ & $1(1 ; 2)$ & $1.59 \pm 0.50$ & $2(1 ; 2)^{*}$ \\
\hline & Thumb & $1.34 \pm 0.48$ & $1(1 ; 2)$ & $1.62 \pm 0.49$ & $2(1 ; 2)^{*}$ \\
\hline & Total sensitivity of the upper limb & $13.36 \pm 3.10$ & $13(11 ; 16)$ & $16.29 \pm 3.06^{* *}$ & $16(15 ; 18)$ \\
\hline
\end{tabular}

CG - control group; MG - main group; ${ }^{*}$ - the difference between the indicators is statistically significant as compared to control group $p<0.05 ;{ }^{* *}-p<0.01$.

10) points; corresponding indicators in MG were 8.90 \pm 2.27 points and $9(7.5 ; 10)$ points respectively. No statistical difference between the groups was revealed ( $\mathrm{p}>0.05)$.

According to the Glasgow Coma Scale, Me (25\%; 75\%) indicator comprised $13(10 ; 13)$ points in CG, and $12(10.5$; 13) points in MG ( $\mathrm{p}>0.05)$.

It should be noted that Albert's Test scores in CG and MG were not statistically different at the first examination: $18.28 \pm 4.82$ points in CG; $18.41 \pm 4.31$ points in $M G$ out of a maximum of 39 points.

Sensorimotor recovery indicators on the Fugl-Meyer scale in CG and MG had no statistical difference at the first examination (Table I). It should be noted that all measured indicators of sensorimotor recovery in CG and MG had significant improvements since the first examination $(\mathrm{p}<0.01)$.

According to the Fugl-Meyer scores of sensorimotor recovery at the final examination, $\pm S D$ indicator of the motor function of the proximal part of the arm in $C G$ comprised $22.81 \pm 5.42$ points out of 36 points possible, with $\mathrm{Me}(25 \% ; 75 \%)$ indicator being $24(18 ; 27)$ points. MG indicator was slightly higher and comprised $27.72 \pm 5.00$ points, with $\mathrm{Me}(25 \% ; 75 \%)$ indicator being $30(25 ; 31.5)$ points. The difference between groups of patients at the final examination was proved significant $(p<0.01)$. As for increase, it comprised 16.41 points in $\mathrm{MG}$ and 12 points in CG. Mean value of MG was 4.91 points higher, which comprised $21.5 \%$ of the final CG indicator.

At the final examination, the average score of the motor function of the hand and radiocarpal joint in CG comprised $16.53 \pm 4.20$ points out of 30 points possible, with $\mathrm{Me}$ (25\%; 75\%) indicator being $17(12 ; 21)$ points (Table 2). MG patients showed slightly better \pm SD indicator, which comprised $20.00 \pm 4.69$ points; Me (25\%; 75\%) indicator was significantly better $(\mathrm{p}<0.01)$ comprising $21(15 ; 24.5)$ points. increase was bigger in MG and comprised 14.93 points, whereas in CG it comprised 11.47 points. Mean 


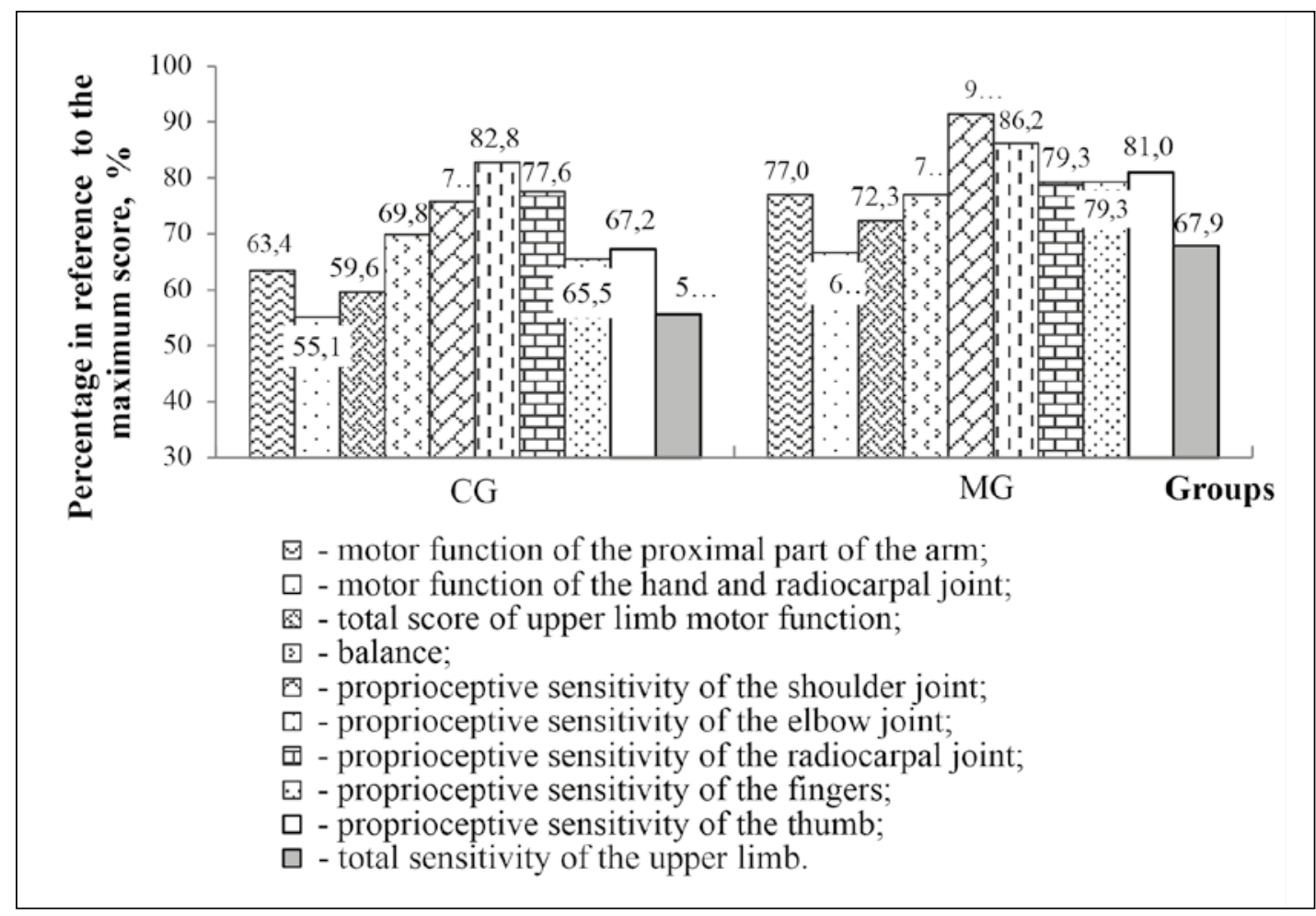

Fig. 1. Comparative final results of the assessment of indicators on the Fugl-Meyer scale in the main (MG) and control (CG) groups of patients

value of MG was 3.47 points higher, which comprised $21 \%$ of the final CG indicator.

The total score of upper limb motor function was significantly better in MG $(\mathrm{p}<0.01)$. MG mean value increased by 31.48 points and amounted to $47.72 \pm 8.81$ points; CG mean value increased by 23.29 points and amounted to $39.34 \pm 8.36$ points. Thus, MG mean value was 8.38 points higher, which comprised $21.3 \%$ of the final CG indicator.

Balance score on the Fugl-Meyer Scale was statistically better in MG when comparing the final scores (Table II). $\mathrm{Me}(25 \% ; 75 \%)$ indicator comprised $12(9.5 ; 12.0)$ points in MG and $11(8 ; 11)$ points in CG $(\mathrm{p}<0.01)$. Mean values increased from $6.24 \pm 0.91$ points to $10.79 \pm 2.30$ points in $\mathrm{MG}$ and from $6.03 \pm 0.91$ points to $9.78 \pm 1.72$ points in CG. Thus, the increase in the groups comprised 4.55 and 3.74 points respectively. MG mean value was 1.01 points higher, which comprised $10.3 \%$ of the final CG indicator.

According to the Fugl-Meyer scores of sensorimotor recovery at the final examination, \pm SD indicator of shoulder joint proprioceptive sensitivity in CG comprised $1.52 \pm 0.51$ points out of 2 points possible, with $\mathrm{Me}(25 \%$; $75 \%)$ indicator being $2(1 ; 2)$ points. MG patients showed slightly higher results which comprised $1.83 \pm 0.38$ points, with Me (25\%; 75\%) indicator being $2(2 ; 2)$ points. The difference between the group scores at the final examination was proved significant $(\mathrm{p}<0.05)$. As for increase, it comprised 0.90 points in $\mathrm{MG}$, and 0.66 points in CG. MG mean value was 0.31 points higher, which comprised $20.4 \%$ of the final CG indicator.

According to the analysis of the final examination scores of elbow joint proprioceptive sensitivity in CG, the average score comprised $1.66 \pm 0.48$ points out of 2 points possible; Me $(25 \% ; 75 \%)$ indicators comprised $2(1 ; 2)$ points. MG patients showed slightly better \pm SD indicator, which amounted to $1.72 \pm 0.45$ points, whereas Me (25\%; 75\%) indicators were similar and had no statistical difference ( $p>0.05$ ). increase comprised 0.90 points in MG and 0.86 points in CG.

The absence of a significant difference in the final scores was also revealed when comparing radiocarpal joint proprioceptive sensitivity in MG and CG ( $>00.05)$. Final Me $(25 \% ; 75 \%)$ indicators comprised $2(1 ; 2)$ points in the groups. \pm SD indicator increased from $0.72 \pm 0.53$ points to $1.55 \pm 0.51$ points out of 2 points possible in CG and from $0.76 \pm 0.56$ to $1.59 \pm 0.50$ points in MG. increase comprised 0.90 points in MG and 0.86 points in CG.

Fingers proprioceptive sensitivity was statistically better in MG. Me (25\%; 75\%) indicator was lower in CG comprising $1(1 ; 2)$ points; $\mathrm{Me}(25 \% ; 75 \%)$ indicator in $\mathrm{MG}$ comprised $2(1 ; 1)$ points $(\mathrm{p}<0,05) . \pm S D$ indicator increased from $0.76 \pm 0.58$ points to $1.31 \pm 0.47$ out of 2 points possible points in CG and from $0.83 \pm 0.60$ to $1.59 \pm 0.50$ points in MG. increase comprised 0.76 points in $\mathrm{MG}$ and 0.55 points in CG. MG mean value was 0.28 points higher, which comprised $21.4 \%$ of the final CG indicator.

At the final examination, the average score of thumb proprioceptive sensitivity comprised $1.34 \pm 0.48$ points out of 2 points possible in CG; $\mathrm{Me}(25 \%$; $75 \%)$ indicator comprised $1(1 ; 2)$ point. MG patients showed slightly better \pm SD indicator which amounted to $1.62 \pm 0.49$ points; $\mathrm{Me}(25 \%$; $75 \%)$ indicator was statistically better $(\mathrm{p}<0.05)$ comprising $2(1 ; 2)$ points. increase was higher in MG comprising 0.72 
points, whereas in CG it comprised 0.48 points. MG mean value was 0.28 points higher, which comprised $20.9 \%$ of the final CG indicator.

According to the Fugl-Meyer scores of sensorimotor recovery at the final examination, $\pm S D$ indicator of the total sensitivity comprised $13.36 \pm 3.10$ points out of 24 points possible in CG. The indicator was slightly higher in MG comprising $16.29 \pm 3.06$ points. The difference between the group scores at the final examination was proved significant $(\mathrm{p}<0.01)$. As for increase, it comprised 5.81 points in $M G$ and 3.33 points in CG. MG mean value was 2.93 points higher, which comprised $21.9 \%$ of the final CG indicator.

Taking into account that Fugl-Meyer scale indicators had different maximum scores, it is necessary to present final indicators in reference to maximum scores (Fig. 1). The analysis of the obtained results revealed that the maximum percentage was appointed to proprioceptive sensitivity of the shoulder joint ( $91.7 \%$ out of the maximum score) in MG, and to proprioceptive sensitivity of the elbow joint (82.8\% out of the maximum score) in CG.

On the other hand, the minimum percentage in $M G$ and CG was appointed to the motor function of the hand and radiocarpal joint $(66.7 \%$ and $55.1 \%$ out of the maximum score, respectively).

\section{DISCUSSION}

First examination of the patients revealed low indicators of upper limb sensorimotor recovery according to the Fugl-Meyer scale. During the course of physical therapy and ergotherapy programs MG and CG patients showed significant improvements of all indicators and total scores of motor function and proprioceptive sensitivity.

At the same time, comparison of the final scores of the samples revealed a number of statistical differences in favor of MG patients, which confirmed the benefits of the combined program of physical therapy and ergotherapy they received.

It should be noted that according to the comparative analysis of final indicators, the largest difference between CG and MG was revealed in shoulder joint proprioceptive sensitivity indicator ( $15.5 \%$ out of the maximum theoretical score). The least difference between the groups was revealed in radiocarpal joint proprioceptive sensitivity indicator (1.7\% out of the maximum score). A fairly small difference was revealed in elbow joint proprioceptive sensitivity indicator $-3.4 \%$ out of the maximum score. Both these indicators had no statistical advantages in any of the samples. In other items of the scale relative advantage (presented in \% out of the maximum possible value) of CG over MG was as follows: motor function of the proximal part of the arm was 13.6; motor function of the hand and radiocarpal joint was $11.6 \%$; total score of upper limb motor function was $12.7 \%$; balance was $7.3 \%$; proprioceptive sensitivity of the fingers was $13.8 \%$; proprioceptive sensitivity of the thumb was $13.8 \%$; total sensitivity of the upper limb was $12.2 \%$.

Thus, the study confirmed positive impact of the combined program of physical therapy and ergotherapy carried out with MG patients on upper limb sensorimotor recovery.

Scientific literature presents studies that both confirm and refute the efficacy of certain interventions for upper limb sensorimotor recovery.

Yun G.J. et al. [20] studied the synergistic effect of mirror therapy and neuromuscular electrical stimulation (NMES) on arm function in stroke patients. Mirror therapy and NMES group patients showed significant improvements in hand, wrist, coordination, and hand extension strength indicators on the Fugl-Meyer scale as compared to the groups receiving only one of the therapies.

At the same time, a blinded randomized controlled trial [21] showed no evidence of mirror therapy efficacy in the early post-stroke period. In this study, the experimental group received mirror therapy, while the control group received sham therapy.

The comparison of impact of movement-based (MMT) and task-based mirror therapies (TMT) on upper limb function improvement in stroke patients confirmed the efficacy of both interventions in patients with mild and moderate hemiplegia caused by stroke. However, according to the study, MMT is more effective than TMT in improving function of hemiplegic upper limbs [22].

The positive effect on fine motor skills recovery with the help of a sensor glove was presented in the study of Prokopenko S.V. et al. [12]. While training, the patient used finger movements to play a computer game. The results of using a sensor glove indicate that a higher level of daily functioning has been achieved after the additional use of sensor glove as a rehabilitation method. Besides, this method is interesting for the patient, improves motivation to exercise involving the patient in the treatment process.

According to the results of the research, combination of ergotherapy and physical therapy is one of the best means for the recovery of post-stroke patients. Ergotherapy has a positive impact on the degree of recovery of certain functions in post-stroke patients, as well as on the level of their independence while performing all major household activities. Rational use of ergotherapy accelerates the recovery of muscle strength, normal joint range of motion, coordinated movements [23].

The study of Park S.E. [24] confirmed the benefits of combining proprioceptive neuromuscular facilitation and oculo-motor exercise for balance indicators recovery in patients with neglect as compared to interventions based on oculo-motor exercise alone or a combination of oculo-motor exercise with functional electrical stimulation.

Our study also confirmed better efficacy of the physical therapy program, which included proprioceptive neuromuscular facilitation.

Positive effect of a scanning and cueing approach (active scanning to the left was encouraged by the therapist, using visual and verbal cues and a mental imagery technique, during reading and copying tasks and simple board games) and a contralesional limb activation approach (functional and goal-oriented left upper-limb activities in neglected hemispace were encouraged) on 
the results of star cancellation test, the line bisection test, and the baking tray task, conducted with patients having neglect syndrome, are presented in the study of Bailey M.J. et al. [16-3]. These results are generally consistent with ours.

Paolucci S. [25] is reported about motor and functional recovery of stroke patients with neglect. Patients were assessed by means of three functional and neurological scales (Rivermead Mobility Index, Barthel Index, Canadian Neurological Scale). Outcomes were significantly improved by the simultaneous presence of a treatment specifically focused on neglect.

Thus, the study confirmed that patients with neglect need special additional interventions within the physical therapy program, as well as better efficacy of therapy combinations, namely proprioceptive neuromuscular facilitation, oculo-motor exercise and visual tracking.

\section{CONCLUSIONS}

Statistical analysis of the Fugl-Meyer scale indicators confirmed that MG had statistical advantages in all studied items of the motor function domain (proximal part of the arm, hand and radiocarpal joint and total score of upper limb), as well as in a number of proprioceptive sensitivity indicators (shoulder joint, fingers, thumb and total sensitivity of upper limb). These results confirm better efficacy of the physical therapy program received by MG patients. In particular, final scores of motor function of the hand and radiocarpal joint comprised $16.53 \pm 4.20$ points out of 30 points possible in CG and $20.00 \pm 4.69$ points in $M G$ $(\mathrm{p}<0.01)$.

\section{REFERENCES}

1. KovalchukV.V., Gusev A.O., Minnullin T.I. et al. Reabilitatsiya patsiyentov posle insul'ta. Kriterii effektivnosti i faktory uspekha: rol' fizicheskoy, neyropsikhologicheskoy i medikamentoznoy terapii [Post-Stroke Rehabilitation. Efficacy Criteria and Success Factors: a Role of Physical, Neuropsychological and Drug Therapy]. Effective Pharmacotherapy. 2017;(19):62-72. (in Russian).

2. Zozulya I.S., Golovchenko Yu.I., Zozulya A.I. et al. Zahal'ni pryntsypy diahnostyky, formuvannya diahnozu, likuvannya ta prohnozuvannya insul'tu [General principles of diagnostic, forming of diagnosis, treatment and prediction of stroke]. Ukrainian Med J.2015;5(109):34-8. (in Ukrainian).

3. Zakaliak N.R., Sprynska O.M. Rol' likuval'noyi himnastyky u vidnovlenni rukhovoyi funktsiyi verkhnikh kintsivok u khvorykh na pislyainsul'tnyy hemiparez [The role of therapeutic gymnastics in the restoration of motor function of the upper extremity in patients with post-stroke hemiparesis]. In: Kopytina YaM, Liannoi M0, editors. Proceedings of the III All-Ukrainian Correspondence Scientific and Practical Internet Conference Health problems, physical therapy, rehabilitation and occupational therapy; 2017 Dec 21; Sumy, Ukraine. Sumy: AS Makarenko SUMPU. 2017: 65-8. (in Ukrainian).

4. Mytskan B., Edynak G., Ostapyak Z. et al. Insul't: prychyny, faktory ryzyku, fizychna reabilitatsiya [Stroke: Causes, Factors of Risk, Physical Rehabilitation]. Physical education, sport and health culture in modern society. 2012;(19):295-302. (in Ukrainian).
5. Russkikh 0.A., Perevoshchikov P.V., Bronnikov V.A. Sindrom ignorirovaniya (neglekta) u postinsul'tnykh bol'nykh i vozmozhnosti neyropsikhologicheskoy reabilitatsii [The syndrome of ignorance (neglect) in post-stroke patients and the possibility of neuropsychological rehabilitation]. In: Krasnoryadtseva OM, editor. Proceedings of the VII Siberian Psychological Forum Complex human studies: psychology; 2017 Nov 28-29; Tomsk, Russia. Tomsk: TSU. 2017; 1: 127-31. (in Russian).

6. Heilman K.M., Valenstein E. Frontal lobe neglect in man. Neurology. 1998:50(5):1202-2-a.

7. Damasio A.R., Damasio H., Chui H.C. Neglect following damage to frontal lobe or basal ganglia. Neuropsychologia. 1980;8:23-32.

8. Mironenko T.V., Vasilenko V.N., Kovalik V.S. Istoriya bolezni: Neglektsindrom u patsiyentov, perenesshikh kardioembolicheskiy insul't [Case records: Neglekt-syndrome in patients undergoing cardioembolic stroke]. University clinic. 2017;13(1):118-22. (in Russian).

9. Evzelman M.A. Narushenie rechi u bolnyih s mozgovyim insultom i ee korrektsiya [Speech impairment in patients with cerebral stroke and its correction]. Orel. 2005:112. (in Russian).

10. Kuznetsova S.M., legorova M.S. Sovremennyye predstavleniya 0 kardioembolicheskom insul'te [Current understanding of cardioembolic stroke]. Doctor. 2003;(3):13-6. (in Russian).

11. Kalinina S.Ya., Semenova T.N., Grigoryeva V.N. Disfunktsiya verkhnikh konechnostey u patsiyentov s insul'tom [Upper limb dysfunction in stroke patients]. Practical medicine. 2017;1(102):40-4. (in Russian).

12. Prokopenko S.V., Mozheyko E.Yu., Alexeevich G.V. Vozmozhnost' vosstanovleniya povyshennoy aktivnosti ruk s pomoshch'yu sensornoy perchatki u patsiyentov s insul'tom [The possibility of restoring the advanced hand activity using the sensorial glove in patients with stroke]. Siberian Medical Review. 2014;(2):72-7. (in Russian).

13. Khizhnikova A.E., Klochkov A.S., Kotov-Smolensky A.M. et al. Dvigatel'noye obucheniye patsiyentov $s$ postinsul'tnym parezom ruki na mekhanoterapevticheskom komplekse [Motor learning of the post-stroke patients presenting with upper limb paresis on the mechanotherapeutic system]. Problems of Balneology, Physiotherapy, and Exercise Therapy. 2018;95(1):20-5. (in Russian).

14. Simpson L.A., Eng J.J. Functional recovery following stroke: capturing changes in upper-extremity function. Neurorehabil Neural Repair.2013;27(3):240-50.

15. Kim Y.M., Chun M.H., Yun G.J. et al. The effect of virtual reality training on unilateral spatial neglect in stroke patients. Ann Rehabil Med. 2011;35(3):309-15.

16. Bailey M.J., Riddoch M.J., Crome P. Treatment of visual neglect in elderly patients with stroke: a single-subject series using either a scanning and cueing strategy or a left-limb activation strategy. Phys Ther. 2002;82(8):782-97.

17. Paolucci S., Antonucci G., Grasso M.G. et al. The role of unilateral spatial neglect in rehabilitation of right brain-damaged ischemic stroke patients: a matched comparison. Arch Phys Med Rehabil. 2001;82(6):743-9.

18. World Medical Association. World Medical Association Declaration of Helsinki: Ethical Principles for Medical Research Involving Human Subjects. JAMA. 2013;310(20):2191-4.

19. Verkhovna Rada of Ukraine. Osnovy zakonodavstva Ukrainy pro okhoronu zdorovia Zakon Ukrayiny 1992, Z. No. 2802-XII [Fundamentals of the Ukrainian Legislation on Health Care Act of 1992, L. No. 2802-XII]. Kyiv: Vidomosti Verkhovnoi Rady Ukrainy [updated 2020 Jun 24; cited 1993 Nov 19]. https://zakon.rada.gov.ua/laws/show/2801-12\#Text . (in Ukrainian). 
20. Yun G.J., Chun M.H., Park J.Y. et al. The synergic effects of mirror therapy and neuromuscular electrical stimulation for hand function in stroke patients. Ann Rehabil Med. 2011;35(3):316-21.

21. Antoniotti P., Veronelli L., Caronni A. et. al. No evidence of effectiveness of mirror therapy early after stroke: an assessor-blinded randomized controlled trial. Clin Rehabil. 2019;33(5):885-93.

22. Bai Z., Zhang J., Zhang Z. et al. Comparison Between Movement-Based and Task-Based Mirror Therapies on Improving Upper Limb Functions in Patients With Stroke: A Pilot Randomized Controlled Trial. Front Neurol. 2019;10:288.

23. Freburger J.K., Dongmei Li., Fraher E.P. Community Use of Physical and Occupational Therapy After Stroke and Risk of Hospital Readmission Arch Phys Med Rehabil. 2018;99(1):26-34.e5. doi: 10.1016/j. apmr.2017.07.011.

24. Park S.E., Min K.O., Lee S.B. et al. Effect of eye movements and proprioceptive neuromuscular facilitation on balance and head alignment in stroke patients with neglect syndrome. J Phys Ther Sci. 2016;28(2):596-601.

25. Paolucci S., Antonucci G., Guariglia C. et al. Facilitatory effect of neglect rehabilitation on the recovery of left hemiplegic stroke patients: a crossover study. J Neurol. 1996;243(4):308-14.

\section{ORCID and contributionship:}

Olena A. Dulo: 0000-0003-0473-5605 A,B,E,F

Yurii M. Dido: 0000-0002-1728-4025 A,C,D,E

\section{Conflict of interest:}

The Authors declare no conflict of interest

\section{CORRESPONDING AUTHOR}

\section{Yurii M. Dido}

Uzhhorod National University

3 Narodna Square, 88000 Uzhhorod, Ukraine

tel: +380509222710

e-mail:yura.dido.1994@gmail.com

Received: 10.10 .2020

Accepted: 02.03.2021

A - Work concept and design, B - Data collection and analysis, C - Responsibility for statistical analysis,

D-Writing the article, $\mathbf{E}$-Critical review, $\mathbf{F}$ - Final approval of the article 